\title{
UPPER GASTROINTESTINAL ENDOSCOPIC BIOPSY; MORPHOLOGICAL SPECTRUM OF LESIONS
}

1. MBBS, M. Phil (Histopathology) Associate Professor Pathology LUMHS Jamshoro.

2. MBBS, PhD (UK)

Assistant Professor

Pathology LUMHS Jamshoro.

3. MBBS, PhD (UK)

Assistant Professor

Pathology LUMHS Jamshoro.

Corresponding Address:

Dr. Farzana Memon

MBBS, M. Phil (Histopathology)

Associate Professor

Pathology LUMHS Jamshoro.

drfarzana_memon@hotmail.com

Article received on:

16/07/2015

Accepted for publication:

07/10/2015

Received after proof reading: 00/00/0000

\section{Dr. Farzana Memon', Dr. Kanwal Baloch², Dr. Ameer Afzal Memon ${ }^{3}$}

ABSTRACT... Background: Upper GI endoscopy is an established procedure for investigating a wide range of upper $\mathrm{Gl}$ conditions especially inflammatory and malignant diseases of stomach and esophagus. A good correlation in diagnosis can be achieved by complementing endoscopic findings with histology of biopsy specimens. Aims and objectives: 1) To evaluate morphological patterns of upper GI conditions. 2) To correlate endoscopic characterization of upper GI lesions with histopathological assessment of biopsy specimens. Study design: A retrospective descriptive study. Period: Four year period from January 2010 to December 2013. Setting: Department of Pathology, LUMHS and were histologically assessed. Material and methods: A total of 433 upper Gl endoscopic biopsies were received. Patient's age, gender and presenting complaints were noted. Results: Stomach was the most frequent site of endoscopic biopsy (51.3\%) followed by esophagus (39\%) and duodenum (9.7\%). Majority of patients (51\%) presented with dysphagia and abdominal pain. Mean age of presentation was 40 years; age range, 9-90 years and male: female ratio is 1:1.6. Esophageal malignancy was the commonest neoplastic lesion with squamous cell carcinoma being the dominant histological type. Interestingly, inflammatory conditions were more common in the stomach. In the duodenum, celiac disease was clinically suspected and histopathological grading confirmed the diagnosis with majority of the cases showing grade-Il pathology. Conclusion: This large retrospective institutional based study showed a good correlation between endoscopic and histological diagnosis. It further shows that esophagus is the predominant site of upper GI malignancy with strong female predominance. Further studies are needed to identify the underlying risk factors.

Key word: $\quad$ Upper Gl endoscopy, Histopathology, Squamous cell carcinoma.

Article Citation: Memon F, Baloch K, Memon AA. Upper gastrointestinal endoscopic biopsy; morphological spectrum of lesions. Professional Med J 2015;22(12):15741579. DOI: $10.17957 / T P M J / 15.3027$

\section{Introduction:}

The upper gastrointestinal flexible fiber optic endoscope was first used in 1968 and proved to be a major breakthrough in the diagnosis of gastrointestinal tract (GIT) lesions. ${ }^{1}$ Upper GIT endoscopy that visualizes the upper part of the GIT up to duodenumis an established mode of investigation and treatment of wide range of upper GIT conditions. It also offers the opportunity for biopsy of neoplastic and non-neoplastic lesions. It is a simple safe and well tolerated procedure with direct visualization of the pathologic site and biopsy leading to early detection of pathologic changes and therefore helps to start appropriate treatment ${ }^{2}$ Endoscopic biopsy examination followed by histopathologic assessment is a convenient procedure and current gold standard for accurate objective assessment of patients with symptoms of upper GIT. It is not only used to diagnose malignant and inflammatory lesions but also for monitoring the course, extent of the disease, response of the therapy and early detection of complications. This is reflected by a rising trend in obtaining mucosal biopsies from the upper $\mathrm{GIT}^{3}$

There is a wide range of pathologic lesions which may affect upper GIT like infectious diseases, inflammatory disorder, mechanical, toxic and physical reactions including radiation injury and neoplasm. ${ }^{4}$ So any patient experiencing the upper abdominal symptoms like pain or dyspepsia is advised to have endoscopic examination followed by histology. The endoscopic lead gastric biopsy not only permits exact diagnosis of specific entity but also provides opportunity to explore H. Pylori 
status. Additionally, it also helps in early detection of malignant lesion, so guides specific medical or surgical therapy. Endoscopic screening may also detect gastric mucosal lesions at an early stage especially atrophy, intestinal metaplasia and dysplasia which can then prevent progress of these lesions to invasive cancer. ${ }^{5}$

Worldwide, esophageal cancer ranks as the $7^{\text {th }}$ most frequent cancer. ${ }^{6}$ More than $90 \%$ of esophageal cancers are squamous cell carcinoma or adenocarcinoma, while other types like melanoma, lymphoma, stromal tumors and neuroendocrine tumors are rarely seen. ${ }^{7}$ Esophageal carcinoma shows wide range of global variation in its incidence and this geographical distribution of cancer can be of great value for generation of epidemiological data. Duodenal biopsies are now commonly performed as a part of Upper Gl endoscopic procedure. Common indication for duodenal biopsy includes peptic ulcer disease, symptoms of malabsorption, neoplasia and infectious enteritis. Another common condition affecting duodenum is Celiac disease which is an enteropathy in certain predisposed individuals who have an inappropriate destructive inflammatory reaction against various proline rich proteins including gliadin in wheat, secalin in rye and horde in in barley. This reaction may initially begin in proximal duodenum and may later involve entire small intestine, stomach and large intestine. ${ }^{8}$

The purpose of this study was to determine the spectrum of morphological lesions of upper GIT and find out the correlation between endoscopic and histopathological diagnosis.

\section{MATERIALS\&METHOD}

A retrospective descriptive study of upper $\mathrm{Gl}$ endoscopic biopsies received in Pathology Department and Diagnostic and Research Laboratory LUMHS during January 2010 to December 2013 was carried out. Patients clinically diagnosed to have upper GIT lesion needing endoscopic biopsy were admitted in gastroenterology unit of Department of Medicine, Liaquat University Hospital. It is a 1200 bedded teaching tertiary care hospital with a wellestablished endoscopic unit. Patients of all ages and both sexes with upper Gl symptoms underwent endoscopic examination and biopsies were taken.

All tissues were fixed in 10\% formaldehyde, routinely process in an automatic tissue processor for 17 hours and then embedded in paraffin wax. Three to five serial sections of four micron thickness were cut on rotatory microtome and analyzed microscopically after staining with hematoxyline and Eosine. Special stains like PAS and Giemsa's stains were used in selected cases.

The demographic data like age, sex, presenting symptoms, site of biopsy and endoscopic findings were retrieved from clinical proforma. Majority of gastric biopsies were taken from antral part of gastric mucosa and show activity by the presence of neutrophils either in lamina propria, within the glands or both. Helicobacter pylori were mostly detected in antral biopsies. Majority of esophageal biopsies were taken from visible ulcerated and friable growth in middle and lower part of esophagus. All duodenal biopsies were taken from $2^{\text {nd }}$ part of duodenum, showing serrated and nodular changes in the mucosa and varied from 1-4 tiny fragments of 2-3 $\mathrm{mm}$ in diameter. Grading for gastric and duodenal biopsies was done according to updated revised Sydney ${ }^{9}$ and modified marsh classificationrespectively ${ }^{10}$ whereas all tumors were classified according to WHO classification.

\section{RESULTS}

Four year retrospective data of upper GIT biopsies was collected from histopathology section, Department of Pathology, Liaquat University of Medical and Health Sciences. A total of 433 cases were included from January 2010 to December 2013. These patients were referred to gastroenterology section of department of Medicine, Liaquat University Hospital Jamshoro for upper gastrointestinal endoscopy. Biopsy specimen were also collected and sent to histopathology section of Diagnostic and research Laboratory for assessment of upper GIT lesions 
as seen by upper GIT endoscopy. The three sites investigated were Esophagus, Stomach and duodenum.

\section{Demographic characteristic and clinical presentation of the population under study}

Out of 433 cases, 200 (46\%) were males and $233(53.8 \%)$ were females with a male to female ratio of 1:1.6. The mean age of presentation was 40 years with the youngest and oldest patients 9 and 90 years old respectively. Majority of the patients either presented with dysphagia (25\%) or abdominal/epigastric pain (37\%). Remaining $38 \%$ patients had non-specific symptoms such as nausea, vomiting, weight loss, hemetemesis, anaemia etc.

\section{Spectrum of upper GIT lesions}

Of all the 433 cases, majority of the biopsies were taken from stomach with a total of 222 (51\%). This is followed by esophagus from where 169 (39\%) tissue samples were taken followed by only $42(10 \%)$ duodenal specimens. The site distribution is illustrated in figure-1. On histology assessment, the total number of diagnosed malignant cases was 144 , most of which i.e. $133(92.36 \%)$ cases were esophageal while only 11 (7.6\%) were gastric (figure-2). No case of duodenal malignancy was identified. Further classification of all the lesions was done based on individual site. The gastric lesions were classified against modified Sydney classification (Table-I) and showed that most of them have chronic gastritis with H.Pylori (40\%) followed by chronic non-specific gastritis with activity (35\%) and without activity (25\%). A contrasting pattern was seen in esophageal cases where most of the lesions (78.6\%) were malignant condition while rest were either inflammatory $(5.9 \%)$, hyperplastic $(9.4 \%)$, dysplastic $(4.1 \%)$ or Barrett's esophagus $(1.7 \%)$. This is given in Table-II. Duodenal lesions were further characterized according to Marsh classification. Majority were diagnosed as grade II (35.7\%) while non-specific duodenitis was seen in $23.8 \%$ as given in Table-III.

\section{Upper GIT biopsy sites}

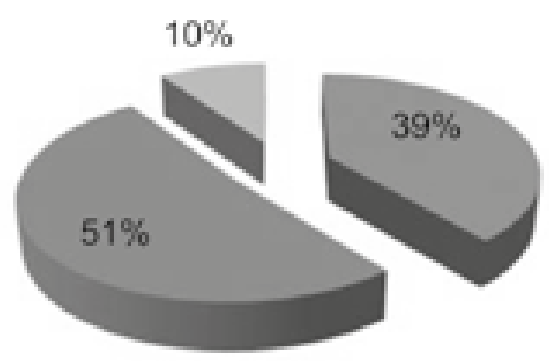

Esophagus =Gastric =Duodenum

Figure-1. Common biopsy sites in the upper GIT lesions

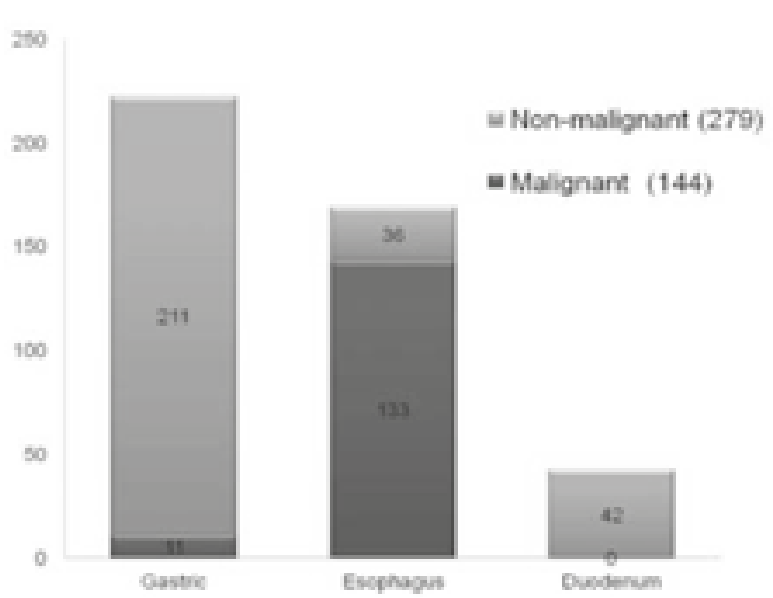

Figure-2. Spectrum of upper GIT lesions based on Histopathology

\begin{tabular}{|l|c|c|}
\hline \multicolumn{1}{|c|}{ Type of Lesion } & No: of Cases & Percentage \\
\hline $\begin{array}{l}\text { Chronic non-specific } \\
\text { gastritis with activity }\end{array}$ & 70 & 31.5 \\
\hline $\begin{array}{l}\text { Chronic inactive gastritis } \\
\text { Chronic gastritis with } \\
\text { H.Pylorl }\end{array}$ & 50 & 22.5 \\
\hline $\begin{array}{l}\text { Chronic gastritis with } \\
\text { intestinal metaplasia and } \\
\text { dysplasia }\end{array}$ & 03 & 36 \\
\hline \begin{tabular}{l} 
Gastric ulcer \\
\hline $\begin{array}{l}\text { Gastric mallgnancy } \\
\text { Normal mucosa }\end{array}$
\end{tabular} & 1.35 \\
\hline $\begin{array}{l}\text { Table-l. Types of histopathologic lesions in stomach } \\
\text { (according to modified Sydney classification) }\end{array}$ & 1.8 \\
\hline
\end{tabular}




\begin{tabular}{|c|c|c|c|c|}
\hline Inflammation & Malignancy & Hyperplastic & Dysplastic & Barrett's exophagus \\
\hline $10(5.9 \%)$ & $133(78.6 \%)$ & $16(9.4 \%)$ & $7(4.1 \%)$ & $3(1.7 \%)$ \\
\hline
\end{tabular}

\begin{tabular}{|c|c|c|c|c|c|}
\hline Non-specific & I & II & Illa & IIIb & IIIc \\
\hline $10(23.8 \%)$ & $8(19.0 \%)$ & $15(35.7 \%)$ & $7(16.6 \%)$ & $2(4.7 \%)$ & - \\
\hline \multicolumn{2}{|c|}{ Table-III. Types of histopathologic lesions in duodenum according to Marsh classification } \\
\hline
\end{tabular}

\begin{tabular}{|c|c|c|c|c|c|c|}
\hline & \multicolumn{3}{|c|}{ Endoscopic findings } & \multicolumn{3}{|c|}{ Histopathologic findings } \\
\hline & Inflammation & Growth & Others & Inflammation & Growth & Others \\
\hline $\begin{array}{c}\text { Gastric } \\
222(51 \%)\end{array}$ & $\begin{array}{c}179 \\
(80.6 \%)\end{array}$ & $11(5.0 \%)$ & $32(14.4 \%)$ & $\begin{array}{c}199 \\
(89.6 \%)\end{array}$ & $\begin{array}{c}12 \\
(5.4 \%)\end{array}$ & $\begin{array}{c}11 \\
(5.9 \%)\end{array}$ \\
\hline $\begin{array}{c}\text { Escophagus } \\
169(39 \%)\end{array}$ & $\begin{array}{c}10 \\
(5.9 \%)\end{array}$ & $\begin{array}{c}143 \\
(184.6 \%)\end{array}$ & $\begin{array}{c}16 \\
(9.4 \%)\end{array}$ & $\begin{array}{c}15 \\
(8.8 \%)\end{array}$ & $\begin{array}{c}133 \\
(78.6 \%)\end{array}$ & $\begin{array}{c}21 \\
(12.4 \%)\end{array}$ \\
\hline $\begin{array}{l}\text { Duodenal } \\
42(9.7 \%)\end{array}$ & $\begin{array}{c}06 \\
(14.2 \%)\end{array}$ & - & $36(85.7 \%)$ & $\begin{array}{c}10 \\
(23.8 \%)\end{array}$ & - & $\begin{array}{c}32 \\
(76.1 \%)\end{array}$ \\
\hline
\end{tabular}

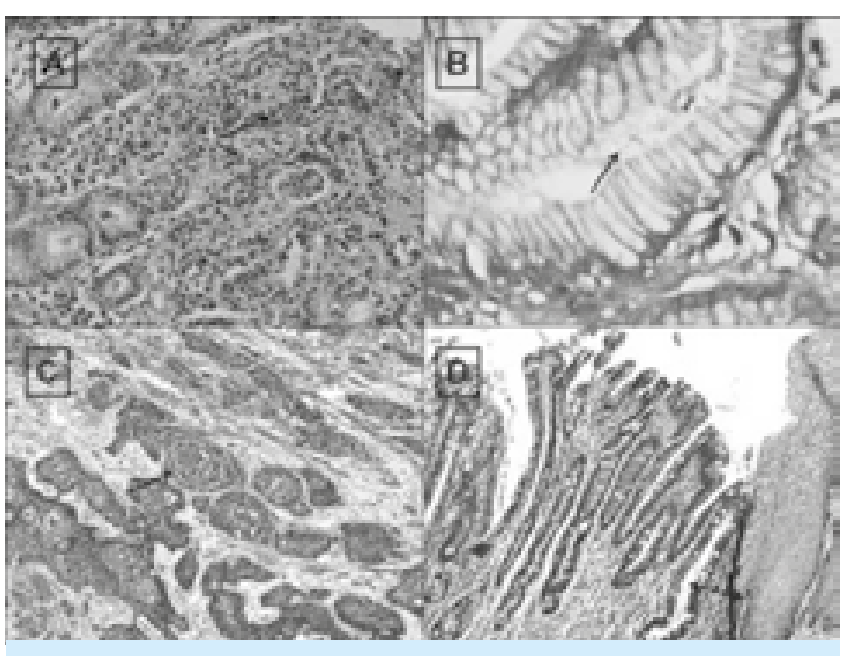

Figure-3. Images of slides stained for histopathological assessment

A) H\& E stained slide of gastric mucosa (antrum) showing mucosal glands diffusely infiltrated by mixed inflammatory cells

B) Giemsa stained slide showing gastric mucosal pits with presence of $\mathrm{H}$-Pylori

X) H \& E stained slide of esophsgea; I growth showing

$\Delta)$ nests of malignant squamous epithelial cells with pearl formation

D) $H \& E$ stained slide from gastroesophageal junction showing stratified squamous epithelium with metaplastic columnar epithelium.

\section{DISCUSSION}

Current standard of care for most patients with symptoms of upper GIT with suspicious lesions consists of initial endoscopic examination followed by histopathology. The individual accuracy and sensitivity of these techniques in the diagnosis of any lesions is subjective to the operator's ability to target site of pathology. This can be greatly improved by combining the two techniques. Furthermore it is important to look at common diseases that affect people in our part of the world in order to understand various epidemiological risk factors involved in the pathogenesis of these conditions. To our knowledge, this is one of the largest studies with more than 400 hundred patients which looked at the range of diseases which affect upper part of GIT and correlation between endoscopy and histopathology in their diagnosis.

Most of the patients presenting with the symptoms were females and presented in the fourth decade of life. These patients with the symptoms of dysphagia or abdominal pain mostly had a lesion suspected in stomach followed by esophagus and duodenum. Our results show consensus with ${ }^{2}$ Sandhya panjeeta gulia et al and ${ }^{3}$ Karish nappa rashmi et al. A number of pathologies can affect all these sites and the most alarming of these is malignancy. Despite the fact that majority of lesions were suspected in stomach, most of these were identified as benign or inflammatory in nature. Chronic gastric was the most common diagnosis with almost a third of these patients had an associated $\mathrm{H}$ pylori infection these result are comparable with studies of ${ }^{11}$ saeed Afzal et al who also reported Chronic gastritis as most common diagnosis and $1 / 3$ of these patients showed association with $\mathrm{H}$. Pyelori. Eleven cases of gastric malignancies were diagnosed on histopathology as gastric adenocarcinoma in line with other studies Parlo or $\mathrm{K}$ et $\mathrm{al}^{16}$ in their study shows 
$56 \%$ of gastric malignancy. A contrasting pattern was observed in esophageal cases which mostly turned out to be squamous cell carcinoma of esophagus. A rising pattern of esophageal malignancy was observed in females ${ }^{15}$ as earlier reports show a male predominance ${ }^{12,13,14}$ which may be due to more exposure of risk factors. Our results show high incidence of esophageal malignancy in females and this may be due to changing socioeconomic habits or improved healthcare facilities to females of rural areas.

Duodenum has a rich rapidly regenerating epithelial lining which can easily be affected by any inflammatory insult like that seen in celiac disease. In this disease, the three prominent changes are increased intraepithelial lymphocytes, crypts hyperplasia and villous atrophy. In our study, celiac disease was suspected in majority of patients with duodenal biopsy but most of these patients were diagnosed with either grade II or mild celiac disease (35\%) with increased intraepithelial lymphocytic infiltration and crypts hyperplasia but no villous atrophy or non-specific duodenitis (23\%) with few inflammatory cells and absence of hyperplasia and atrophy. ${ }^{10,17}$

We next wanted to compare our diagnosis with the demographic parameters. Intriguingly, females had a higher incidence of esophageal malignancy when compared to males. This is in contrast to earlier reports suggesting a male predominance for esophageal cancer. This is mainly attributed to the cigarette smoking, alcoholism and other dietary habits. The changing pattern observed in our patient population could be due to increasing smoking trend in females or increasing awareness leading to improved screening methods leading to early diagnosis. It could also be down to higher prevalence of iron deficiency anemia in female, leading to esophageal webs leading to the Plumner vnson syndrome. The triad consists of iron deficiency anemia, esophageal webs and glossitis.

Finally, the ability of the two techniques for diagnosis of these lesions was compared. Our data suggested that in case of visible growth or malignancy, the two techniques correlated well with almost similar number of cases detected by each. However, histopathology significantly improved diagnosis of inflammatory lesions. Thus the two techniques complement each other in the management of patients with the suspected upper GIT lesions. Histopathology gives a deeper insight into changes at the molecular level.

\section{CONCLUSION}

This study shows a good correlation between endoscopic and histopathology diagnosis. It further shows that oesophagus is the predominant site of the upper GIT malignancy and squamous cell carcinoma is the common histological type and also shows a strong female predominance and further studies are required to study the underlying risk factors especially in females.

Copyright $(07$ Oct, 2015.

\section{REFFERENCES}

1. Black stone MO. Endoscopic interpretation normal and pathologic appearance of the gastrointestinal tract. Raven Press New York 1984;1:13-15.

2. Sandhya panjeta. Gulia et al. Interpretation of upper gastrointestinal tract endoscopic mucosa biopsies a study conducted in teaching hospital in puducherry india. International Journal of medical and health siences 2012:1:13.

3. Karish nappa rashmi. Horakerappa MS, Ali Karar Ghouri Mangala. A study on histopathologic spectrum of upper gastro intestinal tract endoscopic biopsies Int J Medical Res Health Sciences 2013;2 (3):418-424.

4. Rosai $\mathrm{J}$ in : Rosai and Ackerman's surgical pathology $9^{\text {th }}$ ed. St louis: Mosby 2004 PP648-11.

5. Barr H. Endoscopic screening for upper gastrointestinal malignancy westboy $\mathrm{D}$. Lombrd M. In therapeutic gastrointestinal endoscopy. Martin dumits Itd (UK) 2002;54-56.

6. Enzinger Pc, mayer Rj. Esophageal cancer. M. Engle J. Med 2003;349:2241-52.

7. Gabbert HE, shimoda T, Hainant P, Nakamuray, filed JK, I noue $\mathrm{H}$. Squamous cell carcinoma of the esophagus. In Hamilton SR. Altonen LD editors world health organization, classification of Tumors. Pathology and genetics. Tumors of digestive system LYMIARC press 2000. PP11-9.

8. Jeffery gold smith. Biopsy approach to duodenal mucosal biopsy. HMS postgraduate course Department of Pathology Bostan and Harvard medical school.

9. Dizon MF. Geneta RM, yardly JH, correa P, et al calssification and grading of gastritis. The update Sydney system. Amj surgi path 1996;20 1161-81.

10. Oberluber G, granditsch G, voselrang $\mathrm{H}$; The histopathology of celiac disese; time for a standardized report scheme for pathologist, European Journal of gastroenterology and hepatology 1999,11:1195-1194. 
11. Saeed Afzal, Mumtaz Ahmed, Azhar Mubrik, Farrukh Saeed, Shahid Rafi, Nasir Saleem, Ayaz Hussain, Morphological spectrum of Gastric lesion endoscopic biopsy findings Pakistan Armed Forces Medical Journal 2006,2 (6).

12. Uzma Bukhari, Rahim Siyal, Fayaz Ahmed, Javed Hussain Memon, Oesophageal carcinoma. A reveiw of endoscopic biopsies, Pak J Med Sciences 2009; 25 (5); 845-848.

13. Bhurgari $Y$, Faridi N. Kazi LA, Ali SK, Bhurgari $H$. Usman A et al, cancer esophagus Karachi 1995-2002; epidemiology risk factors and trends J Pak Med Assoc. 2004;54 (7):345-8.

14. Anwar Ali, Muhammad Naeem, Taj Muhammad Khan oesophageal cancer in northern areas of Pakistan
Ayub Med coll abbotabad 2009;21 (2)148-50.

15. Bijan Ziain Vahid Montazeri, Raza Khazaiee, shah sam amini, Esophageal cancer occurence in south eastern Iran. J Res Med Sci ,2010 sept-oct:15 (5);290291.

16. Parloor K, Sarpangala MK. Narik RCN. Histopathology diagnosis of gastric biopsies in correlation with endoscopy a study in a tertory care centre. Adv lab Med Int 2013; 3(3); 22-31.

17. Marsh MN Gluten, major histocompatibility complex and the small intestine. A molecular and immunological approach to the specturm of gluten sensitivity (Celiac sprue) gastric enterology 1992.102;330-354.

\section{"The master has failed more times than the beginner has even tried."}

\section{Unknown}

\section{AUTHORSHIP AND CONTRIBUTION DECLARATION}

\begin{tabular}{|c|l|l|l|}
\hline Sr. \# & \multicolumn{1}{|c|}{ Author-s Full Name } & \multicolumn{1}{|c|}{ Contribution to the paper } & Author=s Signature \\
\hline 1 & Dr. Farzana Memon & $\begin{array}{l}\text { Collection of data, analysis } \\
\text { and manus script writing } \\
\text { Drafting the article and } \\
\text { finalizing the manu script } \\
\text { Statistical analysis }\end{array}$ \\
\hline 3 & Dr. Kanwal Baloch & Dr. Ameer Afzal Memon &
\end{tabular}

